\title{
Procedure Portion or Totality
}

National Cancer Institute

\section{Source}

National Cancer Institute. Procedure Portion or Totality. NCI Thesaurus. Code C117528.

A qualifier for the arrangement or apportioning of an entity within a body part, region or organ for the procedure. 